\title{
Tutorials to support learning: Experiences of nursing students in a competency-based nursing programme
}

E Mukurunge, MNsg; M Shawa, MPH; T Nyoni, Diploma in Midwifery; P Mutimbe, Diploma in Midwifery; R Mahomaile, Diploma in Midwifery; K Mokhele, Diploma in Midwifery; B Masava, MPhil

Paray School of Nursing, Thaba Tseka, Lesotho

Corresponding author: E Mukurunge (evamukurunge@gmail.com)

\section{Why was the idea necessary (problem)?}

Nursing education institutions (NEIs) in Lesotho have adopted competencybased education in undergraduate nursing programmes. ${ }^{[1]}$ In preparation for class, nursing students are expected to engage with learning material. This material includes research articles, specific textbook sections, best practice guidelines and videos, which are sources of essential foundational knowledge. During class, educators co-construct knowledge with students by applying foundational knowledge to specific scenarios. Foundational knowledge influences nursing students' critical thinking and reasoning, which are essential in nursing care. The educators in this setting have expressed concern regarding first-year nursing students' lack of preparedness for class activities, attributing it to students' lack of self-directedness. ${ }^{[1]}$

One of the NEIs introduced tutorials as a strategy to improve nursing students' engagement with the learning material. The authors describe the experiences of first-year nursing students regarding the tutorial sessions.

\section{What was tried (approach)?}

Alumni with experience of the same curriculum model were employed as tutors to co-ordinate the tutorial sessions. These tutorials were presented in 1-hour group or individualised sessions, focusing on students' selfidentified learning needs. The group tutorial sessions were integrated into the mainstream timetable, while individual appointments were made at the discretion of the students and recommendation of the nurse educators. Data were collected from first-year nursing students $(N=30)$ through qualitative narrative reports. The participants were asked to describe their experiences of the tutorial sessions at their NEI. The collected data were thematically analysed.

Ethical approval was granted by the Ministry of Health, Lesotho (ref. no. 68-2018) and all participants gave informed consent.

\section{What were the lessons learnt (outcomes)?}

Using level 1 of Kirkpatrick's model, ${ }^{[2,3]}$ results revealed that tutorials are a less formal support strategy where interactive and friendly games were used to make learning interesting for nursing students. Participants indicated that individualised attention and small-group discussions were approaches to learning that clarified concepts. Engagement with activities during tutorials led to participants discovering their own learning styles, which enhanced their understanding of concepts. Participants generally expressed the need for more time allocation to tutorial sessions to maximise the benefits. Nurse educators expressed an improvement in nursing students' participation following their engagement in tutorials.

\section{Conclusions}

First-year nursing students may struggle to adjust to the learning strategies in nursing education. Therefore, NEIs should establish support strategies for students to enhance learning. Tutorials have the potential to improve the learning experience of nursing students. To maximise benefits from tutorial sessions, NEIs should incorporate games and small-group discussions and allow for individual consultations with tutors, as well as allocating enough time for tutorial sessions.

\section{Declaration. None.}

Acknowledgements. The authors acknowledge Dr C N Nyoni (University of the Free State) for his expert input and for critically reading this manuscript, Ms M Nkaki (Paray School of Nursing) and Mrs T Dyamdeki (Paray School of Nursing) for their contribution in the conceptualisation of the project. Paray School of Nursing is acknowledged for providing the platform to develop the project. Author contributions. All authors contributed to the conceptualisation, design and execution of this study. All authors equally contributed to the writing of the article. Funding. None.

Conflicts of interest. None.

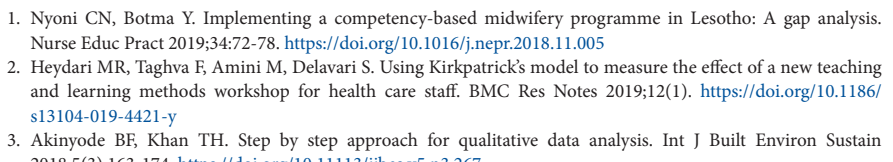
and learning methods workshop for health care staff. BMC Res Notes 2019;12(1). https://doi.org/10.1186 s13104-019-4421-y

3. Akinyode BF, Khan TH. Step by step approach for qualitative data analysis. Int J Built Environ Sustain 2018;5(3):163-174. https://doi.org/10.11113/ijbes.v5.n3.267

Accepted 13 July 2020.

Afr J Health Professions Educ 2020;12(3):96. https://doi.org/10.7196/AJHPE.2020.v12i3.1383 